\title{
Coma After Quetiapine Fumarate Intentional Overdose in a 71-year-old Man: A Case Report
}

\author{
S. Gibiino $\cdot$ A. Trappoli $\cdot$ B. Balzarro $\cdot$ \\ A. R. Atti $\cdot$ D. De Ronchi
}

Published online: 14 February 2015

(C) The Author(s) 2015. This article is published with open access at Springerlink.com

\begin{abstract}
A 71-year-old man developed coma with severe respiratory failure, hypotension, and tachycardia induced by the intentional ingestion of quetiapine fumarate extended release (XR) $20 \mathrm{~g}$. At the time, he had been treated for bipolar depression with venlafaxine $75 \mathrm{mg} /$ day, lamotrigine $100 \mathrm{mg} /$ day, pregabalin $75 \mathrm{mg} /$ day, and quetiapine $\mathrm{XR}$ $400 \mathrm{mg} /$ day for approximately 1 year. Comorbidities were hypertension treated with metoprolol, diabetes mellitus type 2 treated with metformin, and benign prostatic hyperplasia treated with silodosin. In the emergency room, about $4 \mathrm{~h}$ after ingestion of quetiapine fumarate XR, the presenting symptomatology was characterized by coma (Glasgow Coma Scale score 3), hypotension (blood pressure [BP] 90/60 mmHg), tachycardia (electrocardiogram [ECG] showed sinus tachycardia with heart rate 120 beats per minute and a QTc of $499 \mathrm{~ms}$ ). A gastric lavage was performed and activated charcoal $50 \mathrm{~g}$ and magnesium sulfate $30 \mathrm{~g}$ was administered. About $6 \mathrm{~h}$ after ingestion, he developed marked desaturation and underwent mechanical ventilation; $13 \mathrm{~h}$ after ingestion, a severe hypotensive episode followed (BP 70/40), which was treated with an infusion of ringer lactate $500 \mathrm{cc}$. On the $3 \mathrm{rd}$ day after intentional overdose, an episode of agitation occurred; 4 days after ingestion, the quetiapine plasma level was found to be $42 \mathrm{ng} / \mathrm{ml}$ (within therapeutic range). At 5 days after ingestion, the patient developed septicemia caused by staphylococci (probably originating from the central vein catheter), which was treated with antibiotic therapy. On days 10 and 18 after the suicide attempt, two episodes of
\end{abstract}

S. Gibiino $(\bowtie) \cdot$ A. Trappoli · B. Balzarro

A. R. Atti - D. De Ronchi

Department of Biomedical and Neuromotor Sciences, University

of Bologna, Viale C. Pepoli 5, 40123 Bologna, Italy

e-mail: sara.gibiino@studio.unibo.it paroxysmal supraventricular tachycardia (PSVT) occurred and were successfully treated with intravenous adenosine triphosphate. The patient recovered completely without residual symptoms. In line with literature data, in this case report, symptoms of quetiapine overdose were tachycardia, agitation, hypotension, QT interval prolongation, and coma. A causal relationship between PSVT and quetiapine intoxication seems quite unlikely due to the drug level.

\section{Key Points}

Quetiapine is included as a first-line recommendation in recent guidelines for bipolar depression, with evidence of possible benefit in elderly patients who otherwise have a high suicidal risk.

In elderly patients, symptoms of quetiapine overdose are tachycardia, agitation, hypotension, QT interval prolongation, and coma.

Early intervention, rapid transfer to an intensive care unit, and no evidence of co-ingestion of other drugs or alcohol could be associated with a good prognosis.

In case of intoxication, the possibility of early screening of a broader group of drugs, including the widespread second-generation antipsychotics, could be useful to improve clinical practice.

\section{Introduction}

Quetiapine is an orally administered atypical antipsychotic of the dibenzothiazepine class indicated for the treatment 
of schizophrenia and bipolar disorder, including bipolar depression. It is available in strengths ranging from 25 to $400 \mathrm{mg}$ and has been shown to be effective over a broad dose range (up to $800 \mathrm{mg} /$ day). Plasma concentrations associated with efficacy are $20-300 \mathrm{ng} / \mathrm{ml}$ [1]. Quetiapine is rapidly absorbed orally, with a median time to reach maximum observed plasma concentrations of $1-2 \mathrm{~h}$ for the immediate-release formulation and of about $5 \mathrm{~h}$ for the extended-release (XR) formulation. Single- and multipledose studies have demonstrated linear pharmacokinetics in the clinical dose range, with a half-life of about $7 \mathrm{~h}$. Its volume of distribution is reported to be $5-141 / \mathrm{kg}$, and protein binding is approximately $83 \%$ [2-4].

The primary route of elimination is hepatic metabolism by cytochrome P450 isoenzyme (CYP) 3A4 [3]. Various metabolites have been detected; two are reported to be pharmacologically active. Their maximal concentrations were reported to be $12 \%$ of plasma concentration of the parent drug and are therefore unlikely to contribute substantially to the pharmacologic effect under normal conditions [3].

From a pharmacodynamic perspective, it is structurally related to clozapine, but it does not appear to cause clinically significant hematologic adverse effects such as the agranulocytosis seen with clozapine [5]. It has moderate affinity for serotonin 5-HT2A receptors (antagonistic effect), $\alpha 1$ adrenergic receptors (antagonistic effect), muscarinic (weak anticholinergic effect) and histaminergic (antagonistic effect) receptors, minor affinity for dopamine D2 (antagonistic effect) and 5HT1A receptors (partial agonistic effect), and very low affinity for 5HT2C, $\alpha 2$, and D1 receptors (antagonistic effect) [3, 6].

Reports of acute quetiapine overdose are rare in preclinical trials, and it has long been deemed safer than other antipsychotic agents [7]. Nonetheless, quetiapine is not devoid of overdose toxicity and has been reported to have the highest rate of deaths per million prescriptions (clozapine excluded) [8]. Indeed, an increasing number of studies have provided detailed clinical and analytical data on severe cases of overdose with quetiapine, including cases of fatalities [2, 7, 9-19]. The main clinical manifestations of overdose include mild hypotension, central nervous system depression with the need for intubation and mechanical ventilation in some cases, and sinus tachycardia. Cardiac dysrhythmias occur infrequently, and few patients are reported to develop seizures in large overdoses [9, 11]. Generally, the adverse effects like tachycardia, hypotension, and somnolence associated with quetiapine, particularly after ingestion of an overdose, can be explained by blockage of the $\alpha 1$-adrenergic, muscarinic, and histamine receptors. Symptoms of central nervous system depression such as somnolence and drowsiness are also mediated through the antagonistic effect of quetiapine on serotonergic 5-HT2A and the moderate antagonistic effect on dopamine D2 receptors [3].

Quetiapine is included as a first-line recommendation in recent guidelines for bipolar depression [20], with several trials demonstrating its efficacy as monotherapy in acute treatments of adults with bipolar depression. Its efficacy in elderly patients is based on case reports and open-label studies, with evidence of possible benefits in elderly patients with mood disorders due to a low potential for extrapyramidal symptoms (EPS) [21].

Nevertheless, use of antipsychotic drugs in geriatric psychiatric disorders raises a number of questions about use in different conditions (e.g., delirium, dementia, schizophrenia, delusional disorder, psychotic mood disorders) and different patients (comorbid conditions or history of side effects, dosing strategies, duration of treatment, and medication combinations) [22], as well as the potentially inappropriate use among older adults [23].

Further, the risk of suicide is very high among older men, especially old Caucasian men [24], and suicidal ideation is a core phenomenon in all psychiatric diseases in elderly individuals [25]. Close monitoring of suicidal risk is required during treatment with quetiapine, especially in patients with bipolar depression who are at particularly high risk of suicide [26] and in young adults, as reported in the product summary (http://www.medicines.org.uk/emc/ medicine/21175/SPC/).

We present here a case of intentional overdose of quetiapine, resulting in coma with severe respiratory failure, hypotension, and tachycardia, and a favorable outcome.

\section{Case Report}

A 71-year-old man was admitted to our emergency department after his wife found him lying unconscious on the ground. Also found in close proximity to the patient were five empty blister packs of ten tablets each of quetiapine XR $400 \mathrm{mg}$ (20 g of quetiapine in total). Alcohol and illicit drug use was denied by his wife, and no other empty boxes of drugs were found. Clinicians strongly suspected the ingestion of that amount of quetiapine by the empty blisters found close to him, by the clinical presentation, and by the psychiatric history and recent psychiatric symptomatology (furthermore, during subsequent hospitalisation, the patient confirmed the voluntary ingestion of that type and quantity of medication). The psychiatric history was in fact characterized by the presence of a diagnosis of bipolar disorder with depressive episodes and depressive symptoms prevailing, with two previous suicide attempts by intentional overdose with drugs and asphyxia, both as potentially harmful as the present one. He was currently being treated for psychiatric illness with venlafaxine $75 \mathrm{mg}$, lamotrigine 
$100 \mathrm{mg}$, pregabalin $75 \mathrm{mg}$, and quetiapine XR $400 \mathrm{mg}$ per day. In particular, the patient had been receiving quetiapine for approximately 1 year. His medical history was notable for hypertension treated with beta blockers (currently metoprolol), diabetes mellitus type 2 treated with metformin, and benign prostatic hyperplasia treated with silodosin. None of these drugs are known to interfere with quetiapine metabolism [27].

The patient arrived at the emergency room approximately $4 \mathrm{~h}$ after ingestion (for a timeline of the events, see Fig. 1; Table 1). On admission, the Glasgow Coma Scale score was 3. Vital signs were as follows: blood pressure $90 / 60 \mathrm{mmHg}$, increasing to $115 / 70$ after infusion of saline $2,000 \mathrm{ml}$; respiratory rate 18 breaths per minute; oxygen saturation $88 \%$; pupils were of equal and normal diameter; there was no evidence of trauma, infection, myoclonus, or muscle rigidity. Electrocardiogram (ECG) showed sinus tachycardia (120 beats per minute), right bundle branch block, extreme right axis deviation as likely left branch hemiblock, poor $\mathrm{R}$ wave progression in the precordial leads, with a QTc of $499 \mathrm{~ms}$ (according to Bazett); PR and QRS intervals were 160 and $100 \mathrm{~ms}$, respectively (Fig. 2). Serum chemistry and complete blood count values revealed a slight increase in transaminases (aspartate aminotransferase [AST] $48 \mathrm{U} / \mathrm{L}$ and alanine aminotransferase [ALT] $65 \mathrm{U} / \mathrm{L}$ [normal values (n.v.) AST $<38 \mathrm{U} / \mathrm{L}$ and ALT $<41 \mathrm{U} / \mathrm{L}]$ ), increased myoglobin and creatine kinase $(1,572 \mathrm{ng} / \mathrm{ml}$ and $294 \mathrm{U} / \mathrm{L}$, respectively [n.v. myoglobin $<80 \mathrm{ng} / \mathrm{ml}$ and creatine kinase $<170 \mathrm{U} /$ L]). Serum potassium and magnesium were in the normal range, as were other values. The urine toxicology was negative for illicit drugs and medications (amphetamine, benzodiazepines, barbiturates, cannabinoids, cocaine, methadone, opiates) except for tricyclic antidepressants (TCAs). In cases of suspected intoxication, blood is routinely screened for the following drugs: digoxin, valproic acid, carbamazepine, phenytoin, phenobarbital, and lithium. These screens were all negative, as were alcohol levels. Screening of the medications taken regularly by the patient, inclusive of quetiapine, are not routinely performed. Arterial gas analysis revealed a $\mathrm{pH}$ of 7.34 (decreased to 7.31 in a few hours), $\mathrm{PaCO}_{2} 46 \mathrm{mmHg}, \mathrm{HCO}_{3}$ $24.8 \mathrm{mmol} / \mathrm{L}$, lactate $7.5 \mathrm{mmol} / \mathrm{L}$, and base excess -1.4 (increased to -5.4 in a few hours). In the following hours, with appropriate treatment, the arterial gas analysis values progressively improved to normalize about $21 \mathrm{~h}$ after quetiapine ingestion; in particular, $\mathrm{pH}$ and base excess values reached 7.43 and 4.2 , respectively. The poison control center of Pavia was contacted for the procedures to follow.

Although the latency from ingestion to presentation was suspected to be about $4 \mathrm{~h}$ before arrival, a gastric lavage was performed, followed by administration of activated charcoal $50 \mathrm{~g}$ and magnesium sulfate $30 \mathrm{~g}$ through a nasogastric tube. Spontaneous breathing was supported with a facial mask with reservoir, with an increase of oxygen saturation to $97 \%$, and the patient was transferred to a critical care area about $6 \mathrm{~h}$ after ingestion.

In the intensive care unit (ICU), the patient was quickly intubated for an episode of marked desaturation, and underwent mechanical ventilation with $50 \% \mathrm{FiO}_{2}$ and $8 \mathrm{~cm}$ $\mathrm{H}_{2} \mathrm{O}$ positive end-expiratory pressure (PEEP); a central vein catheter (CVC) and a peripheral catheter were placed in the right subclavian and in the right radial vein, respectively. Bladder catheter and nasogastric tube were also inserted. Sedation was obtained with a low-dose propofol infusion. About $7 \mathrm{~h}$ after arrival in the ICU (approximately $13 \mathrm{~h}$ after ingestion), the patient experienced a severe hypotensive episode (BP 70/40), treated with an infusion of ringer lactate $500 \mathrm{cc}$ with benefit (BP 120/60 after about $2 \mathrm{~h}$ ). Esophagogastroduodenoscopy (EGDS) was performed, with negative results, excluding stasis except for a

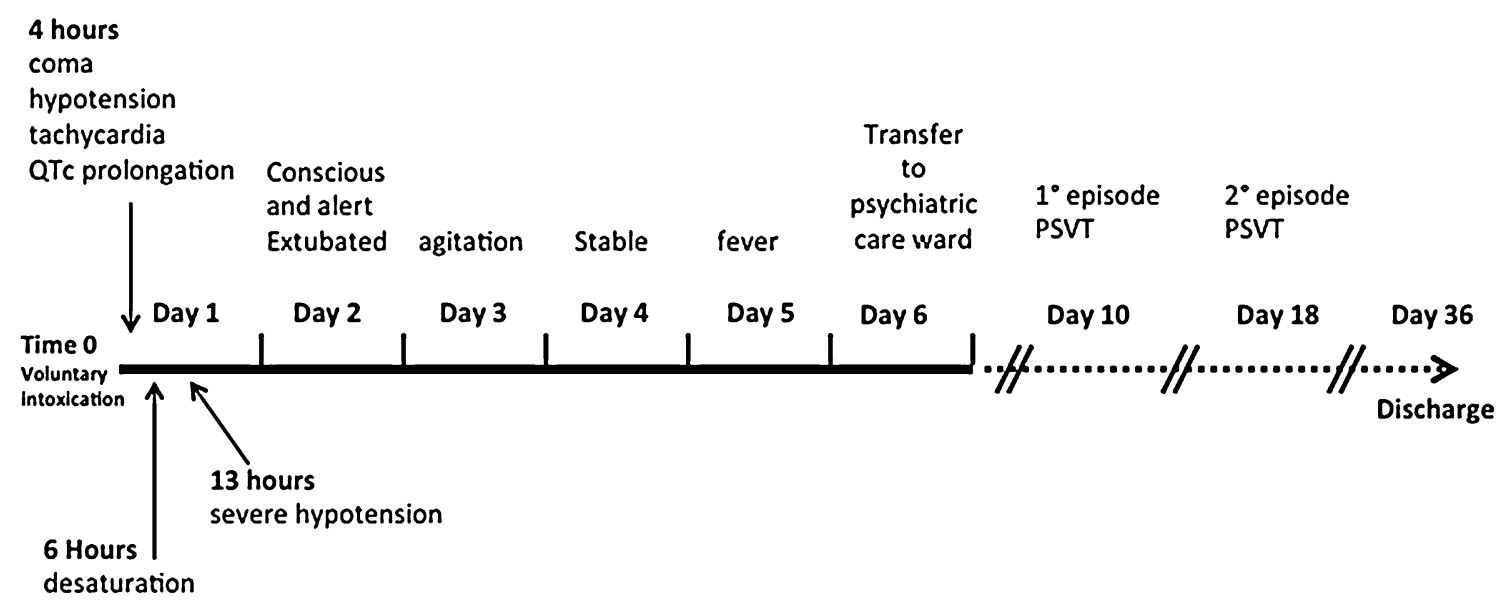

Fig. 1 Timeline of the events 
Table 1 Detailed timeline of the events

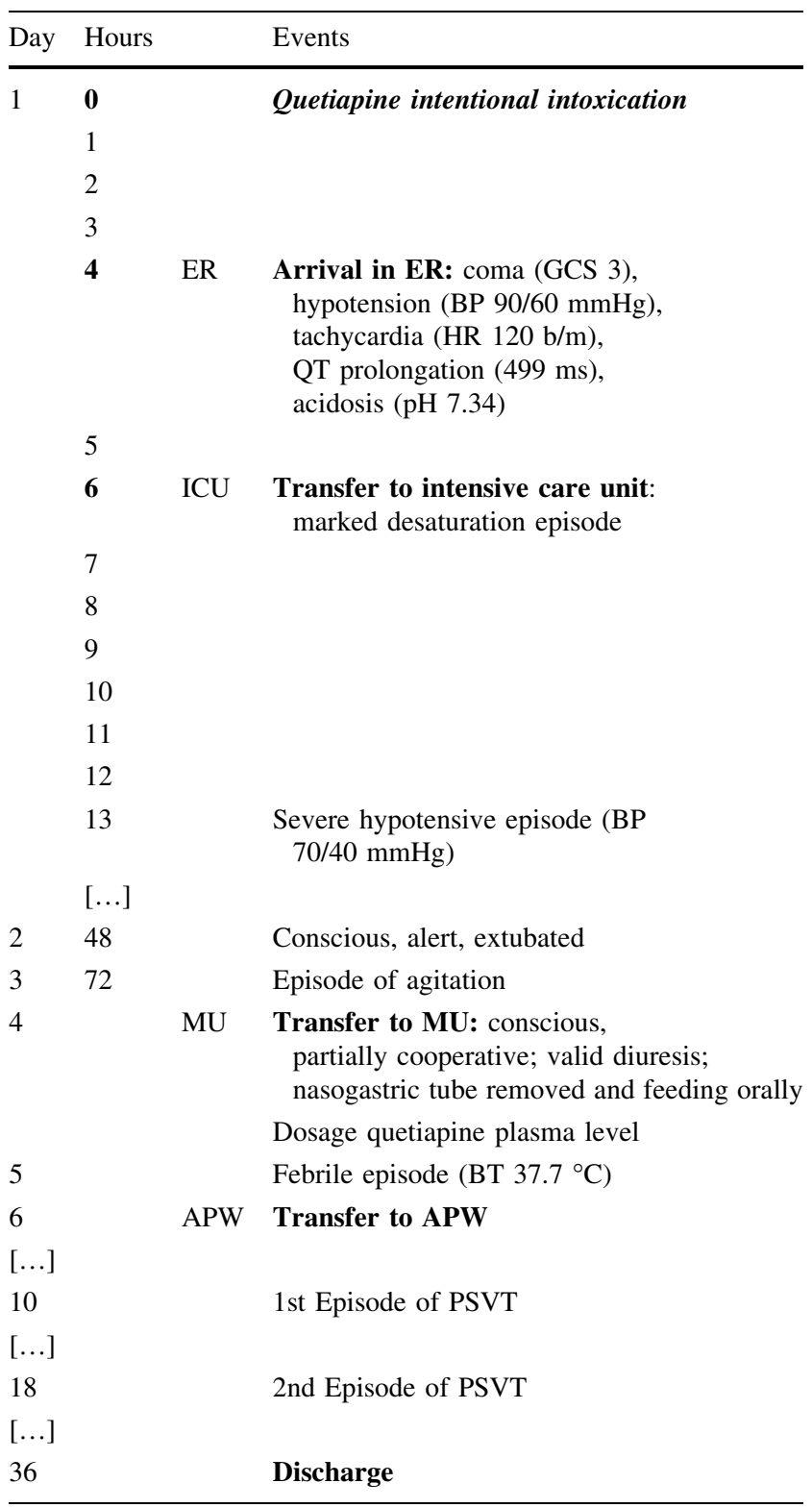

$A C W$ acute psychiatric ward, $B P$ blood pressure, $B T$ body temperature, $E R$ emergency room, $H R$ heart rate, $I C U$ intensive care unit, $M U$ medical unit, $P S V T$ paroxysmal supraventricular tachycardia

low quantity of carbon. By day 2 of hospitalization in the ICU (about $48 \mathrm{~h}$ after ingestion), sedation was discontinued and the patient regained consciousness and became alert and able to follow simple commands. A weaning protocol was started, and the patient was extubated shortly thereafter. By ICU day 3 (about $72 \mathrm{~h}$ after the ingestion), the patient became agitated, and consequently needed sedation. While in the ICU, after the hypotensive episode, the patient was hemodynamically stable, and ECG showed a progressive reduction of heart rate and QTc. On day 4 of hospitalization, the patient was moved to a medical ward. At this time, ECG showed sinus rhythm with a heart rate of
90 beats per minute and a QTc of $411 \mathrm{~ms}$, incomplete right bundle branch block, but no further signs of left branch hemiblock; he was conscious, sometimes agitated, and partially cooperative; diuresis was valid; the nasogastric tube was removed, and oral feeding was possible. On day 4 after ingestion, the quetiapine plasma level was found to be $42 \mathrm{ng} / \mathrm{ml}$.

On day 5 after ingestion, the patient had a body temperature of $37.7^{\circ} \mathrm{C}$, measured during the night, and laboratory tests showed an increase of inflammatory markers (erythrosedimentation rate $81 \mathrm{~mm} / \mathrm{h}$ and polymerase chain reaction [PCR] $27.40 \mathrm{mg} / \mathrm{dL}$ ). A blood sample was positive for Staphylococcus aureus and Staphylococcus lugdunensis. The case was referred to an infectivology consultant, who diagnosed a probable infection starting from the CVC. Following his suggestions to exclude other possible causes or complications, an echocardiogram was performed, which excluded the presence of myocarditis or endocarditis. Cardiac function was as follows: left ventricle of normal size and global and segmental kinetics; mild symmetrical hypertrophy. Ejection fraction (EF) $61.3 \%$ (n.v. $\geq 55$ ); telediastolic (TD) volume $62 \mathrm{ml}$ (n.v. 67-155), telesystolic (TS) volume $24 \mathrm{ml}$ (n.v. 22-58), TD volume/body surface area $31 \mathrm{ml} / \mathrm{m}^{2}$ (n.v. 35-75), TS volume/body surface area $12 \mathrm{ml} / \mathrm{m}^{2}$ (n.v. 12-30). A chest X-ray was also performed, with no evidence of either parenchymal focal lesion or pleural effusion. Antibiotic therapy with amoxicillin clavulanate was started, with progressive improvement of symptoms and laboratory indexes in about 14 days. The CVC and bladder catheter were then removed. At day 6 from ingestion, the patient was voluntarily transferred to an acute psychiatric care unit for further observation and treatment.

Upon the arrival in the acute psychiatric ward (APW) the patient was alert, lucid, oriented, and cooperative; psychomotricity was normal. Mood was only slightly depressed, but the patient reported a strong feeling of intense anxiety and distress. He had insight into the dangerousness of the suicide attempt, and he was aware that it followed a period of emotional stress and depression. Neither abnormal thinking nor alterations of perception were visible. ECG was normal, with a heart rate of about 90 beats per minute. On day 4 in the APW (day 10 from intentional overdose), the patient had an abrupt episode of paroxysmal supraventricular tachycardia (PSVT), with a heart rate of 190 beats per minute, associated with rapid desaturation (Sat $\mathrm{O}_{2} 89 \%$ ), and was treated with a rapid intravenous injection of adenosine triphosphate $6 \mathrm{mg}$ for a first attempt and $12 \mathrm{mg}$ after few minutes. After restoration of a regular sinus rhythm, maintenance therapy was set with diltiazem $90 \mathrm{mg} /$ day. On day 12 of hospitalization in the APW (day 18 from ingestion), the patient experienced a second episode of PSVT, which was again treated with intravenous 


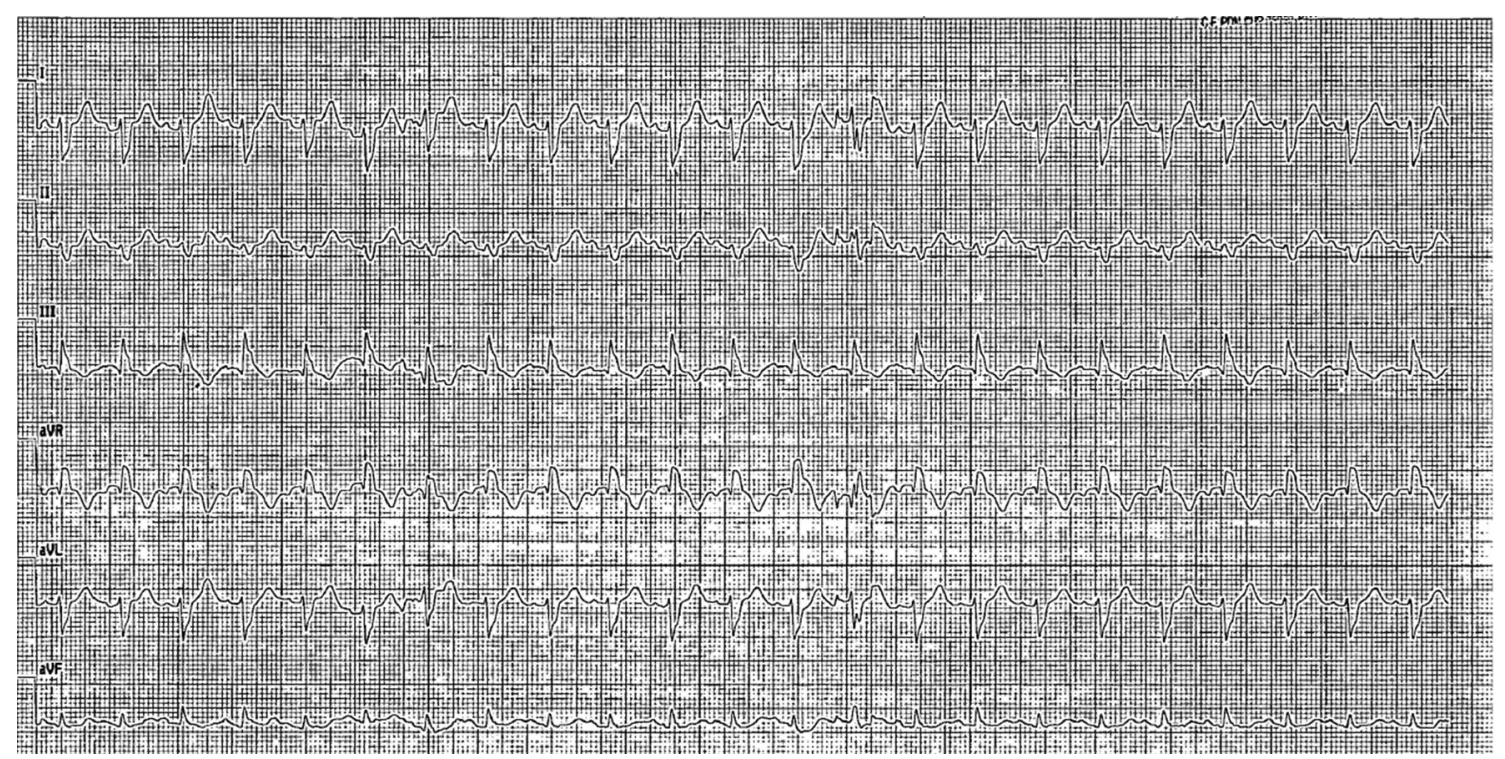

Fig. 2 Initial ECG showed sinus tachycardia (120 beats per minute), right bundle branch block, extreme right axis deviation as likely left branch hemiblock, and poor R-wave progression in the precordial leads

adenosine triphosphate $6 \mathrm{mg}$ with benefit. Prevention therapy with diltiazem was then increased to $180 \mathrm{mg} /$ day, and out-patient follow-up was advised by the consulting cardiologist for a possible curative ablation. In the APW, a specific therapy was gradually set, consisting of aripiprazole $30 \mathrm{mg}$, valproate $1,500 \mathrm{mg}$, sertraline $150 \mathrm{mg}$, and trazodone $100 \mathrm{mg}$ per day. During the remaining period in the APW, there were no other physical problems and an outpatient psychiatric follow-up was decided. The patient was discharged to home on the 36th day after the suicide attempt.

\section{Discussion}

Here we report a case of coma with severe respiratory failure, hypotension, and tachycardia induced by the intentional ingestion of quetiapine fumarate XR $20 \mathrm{~g}$ in a 71-year-old man with bipolar disorder. Further, on day 10 and 18 after voluntary overdose, the patient developed two episodes of PSVT.

To our knowledge, our report is among few clinical cases involving patients older than 70 years $[9,28]$.

The toxicity reported for quetiapine seems to vary widely, with fatalities reported with therapeutic doses [29] as well as with massive ingestions: coma and death have been reported after an acute overdose of $10.8 \mathrm{~g}$, whereas other patients have survived acute overdoses of up to $36 \mathrm{~g}$ [30]. Ongoing chronic treatment with the $3 \mathrm{~A} 4$ inhibitors ketoconazole, fluvoxamine, protease inhibitors, and erythromycin may increase quetiapine toxicity, leading to increased plasma concentration [17, 30, 31]. Additional risk factors include medical comorbidities such as hepatic and cardiac dysfunctions, age, and previous electrolyte imbalances [3, 32].

Among psychiatric medications, the two most commonly suggested mechanisms in cardiac dysrhythmias are sodium channel antagonism (producing prolonged QRS interval duration and ventricular dysrhythmias) and potassium channel antagonism (producing QTc interval prolongation and torsade de pointes). The affinity of quetiapine for cardiac sodium channels is not well described, but a number of quetiapine overdose reports describe QRS interval prolongation similar to the type 1A anti-dysrhythmics [33].

Comparing the potency of potassium channel inhibition with the therapeutic plasma levels of the drugs, the difference between the inhibitory potency and the therapeutic dose is highest in the case of quetiapine (along with olanzapine and risperidone), with thioridazine showing the smallest difference. Some additional cellular effects of particular factors (diseases, electrolytes disturbances, genetic damage, drug interactions) could make the individual vulnerable to arrhythmia [34]. Given all these variables, in our patient, quetiapine overdose could be implicated in early ECG alterations, whilst a possible causal relationship between PSVT and drug intake seems quite unlikely given the very low quetiapine plasma level detected at day 4 (42 ng/ml).

Despite the presence of several risk factors, such as age and hypertension, our patient recovered completely from a high oral overdose of quetiapine, without residual symptoms. Older age is a significant predictor of higher quetiapine plasma concentration, with a mean increase of 
weight-corrected concentration/dose ratio of $11 \%$ per 10 years of age [35]. Unfortunately, we have neither data on quetiapine plasma levels before day 4 nor measurements of other drugs that the patient was taking at the time of overdose. On day 4, quetiapine level was found to be $42 \mathrm{ng} / \mathrm{ml}$, a very low level considering that the target ranges suggested for the treatment of schizophrenia are 50-100, 100-500, and 70-170 ng/ml [20, 36, 37].

The patient's complete recovery may be at least partially attributed to the early intervention (the latency from ingestion to presentation at the emergency room was probably about $4 \mathrm{~h}$ ) and the rapid transfer to an ICU. Further, in our case, there was no evidence of co-ingestion of other drugs or alcohol; drug screening was positive for TCAs, likely due to the cross-reactivity of TCAs with quetiapine [10].

The management of quetiapine intoxication includes supportive care and continuous cardiac monitoring. Activated charcoal can be given for initial decontamination [38]. Gastric lavage is not routinely recommended after $60 \mathrm{~min}[39,40]$; in our case, the latency from ingestion to presentation was uncertain, and a gastric lavage was performed as suggested by the Pavia poison control center. The use of multi-dose activated charcoal could also be considered, despite that its use is not recommended in quetiapine overdoses [41]. Monitoring of cardiac and respiratory function, intravenous access, and a 12-lead ECG is required $[12,40]$. In patients with QTc prolongation, serum potassium and magnesium should be maintained in the high-normal range, and concomitant drugs interfering with quetiapine metabolism should be discontinued [42, 43].

\section{Conclusion}

We presented a case of overdose with quetiapine $20 \mathrm{~g}$ in a 71-year-old man, leading to deep coma, respiratory depression, hypotension, and tachycardia. Further, on day 10 and 18 after overdose, the patient developed two episodes of PSVT, a causal relation of which with intoxication is quite unlikely.

The patient fully recovered without residual symptoms after intense supportive care and close monitoring.

Given the widespread use of quetiapine in psychiatric practice, the present case report helps to better define the safety and risk-benefit profile of this drug.

Acknowledgments The authors acknowledge Dr. Paola Prestinenzi for her contribution in the interpretation of ECGs, and Drs. Anna Crivellari and Federico La Manna for their contribution in pharmacokinetic computations and comments.

Sara Gibiino, Angela Trappoli, Beatrice Balzarro, Anna Rita Atti, and Diana De Ronchi declare that they have no conflict of interest.
No financial support was received for the conduct of this study or preparation of this manuscript.

The patient provided consent for the publication of the data.

Open Access This article is distributed under the terms of the Creative Commons Attribution Noncommercial License which permits any noncommercial use, distribution, and reproduction in any medium, provided the original author(s) and the source are credited.

\section{References}

1. Hasselstrom J, Linnet K. Quetiapine serum concentrations in psychiatric patients: the influence of comedication. Ther Drug Monit. 2004;26(5):486-91.

2. Isbister GK, Friberg LE, Hackett LP, Duffull SB. Pharmacokinetics of quetiapine in overdose and the effect of activated charcoal. Clin Pharmacol Ther. 2007;81(6):821-7.

3. DeVane CL, Nemeroff CB. Clinical pharmacokinetics of quetiapine: an atypical antipsychotic. Clin Pharmacokinet. 2001;40(7): 509-22.

4. Figueroa C, Brecher M, Hamer-Maansson JE, Winter H. Pharmacokinetic profiles of extended release quetiapine fumarate compared with quetiapine immediate release. Prog Neuropsychopharmacol Biol Psychiatry. 2009;33(2):199-204.

5. Borison RL, Arvanitis LA, Miller BG. ICI 204,636, an atypical antipsychotic: efficacy and safety in a multicenter, placebo-controlled trial in patients with schizophrenia. U.S. SEROQUEL Study Group. J Clin Psychopharmacol. 1996;16(2):158-69.

6. Pae CU, Sohi MS, Seo HJ, Serretti A, Patkar AA, Steffens DC, et al. Quetiapine XR: current status for the treatment of major depressive disorder. Prog Neuropsychopharmacol Biol Psychiatry. 2010;34(7):1165-73.

7. Hustey FM. Acute quetiapine poisoning. J Emerg Med. 1999;17(6):995-7.

8. Griffiths C, Flanagan RJ. Fatal poisoning with antipsychotic drugs, England and Wales 1993-2002. J Psychopharmacol (Oxford, England). 2005;19(6):667-74.

9. Ngo A, Ciranni M, Olson KR. Acute quetiapine overdose in adults: a 5-year retrospective case series. Ann Emerg Med. 2008;52(5):541-7.

10. Hunfeld NG, Westerman EM, Boswijk DJ, de Haas JA, van Putten MJ, Touw DJ. Quetiapine in overdosage: a clinical and pharmacokinetic analysis of 14 cases. Ther Drug Monit. 2006;28(2):185-9.

11. Strachan PM, Benoff BA. Mental status change, myoclonus, electrocardiographic changes, and acute respiratory distress syndrome induced by quetiapine overdose. Pharmacotherapy. 2006;26(4):578-82.

12. Balit CR, Isbister GK, Hackett LP, Whyte IM. Quetiapine poisoning: a case series. Ann Emerg Med. 2003;42(6):751-8.

13. Harmon TJ, Benitez JG, Krenzelok EP, Cortes-Belen E. Loss of consciousness from acute quetiapine overdosage. J Toxicol. 1998;36(6):599-602.

14. Pollak PT, Zbuk K. Quetiapine fumarate overdose: clinical and pharmacokinetic lessons from extreme conditions. Clin Pharmacol Ther. 2000;68(1):92-7.

15. Isbister GK, Duffull SB. Quetiapine overdose: predicting intubation, duration of ventilation, cardiac monitoring and the effect of activated charcoal. Int Clin Psychopharmacol. 2009;24(4): 174-80.

16. Fernandes PP, Marcil WA. Death associated with quetiapine overdose. Am J Psychiatry. 2002;159(12):2114. 
17. Langman LJ, Kaliciak HA, Carlyle S. Fatal overdoses associated with quetiapine. J Anal Toxicol. 2004;28(6):520-5.

18. Muller C, Reuter H, Dohmen C. Intoxication after extreme oral overdose of quetiapine to attempt suicide: pharmacological concerns of side effects. Case Reports Med. 2009;2009:371698.

19. Mattoo SK, Shah R, Rajagopal R, Biswas PS, Singh SM. Quetiapine: relatively safe in overdose? Indian $\mathrm{J}$ Psychiatry. 2009;51(2):139-40.

20. Taylor D, Paton C, Kapur S. The Maudsley prescribing guidelines in psychiatry. 11th ed. USA: Wiley-Blackwell; 2012.

21. Sajatovic M, Calabrese JR, Mullen J. Quetiapine for the treatment of bipolar mania in older adults. Bipolar Disord. 2008;10(6): $662-71$.

22. Alexopoulos GS, Streim J, Carpenter D, Docherty JP. Using antipsychotic agents in older patients. J Clin Psychiatry. 2004;65(Suppl 2):5-99 (discussion 100-2; quiz 3-4).

23. Tosato M, Landi F, Martone AM, Cherubini A, Corsonello A, Volpato S, et al. Potentially inappropriate drug use among hospitalised older adults: results from the CRIME study. Age Ageing. 2014;43(6):767-73.

24. Bruce ML, Ten Have TR, Reynolds CF 3rd, Katz II, Schulberg $\mathrm{HC}$, Mulsant $\mathrm{BH}$, et al. Reducing suicidal ideation and depressive symptoms in depressed older primary care patients: a randomized controlled trial. JAMA. 2004;291(9):1081-91.

25. Lindner R, Foerster R, von Renteln-Kruse W. Physical distress and relationship problems: exploring the psychosocial and intrapsychic world of suicidal geriatric patients. Z Gerontol Geriatr. 2014;47(6):502-7.

26. Chang JC, Chen HH, Yen AM, Chen SL, Lee CS. Survival of bipolar depression, other type of depression and comorbid ailments: ten-year longitudinal follow-up of 10,922 Taiwanese patients with depressive disorders (KCIS no. PSY1). J Psychiatr Res. 2012;46(11):1442-8.

27. Spina E, de Leon J. Metabolic drug interactions with newer antipsychotics: a comparative review. Basic Clin Pharmacol Toxicol. 2007;100(1):4-22.

28. Pilgrim JL, Drummer OH. The toxicology and comorbidities of fatal cases involving quetiapine. Forensic Sci Med Pathol. 2013;9(2):170-6.

29. Litovitz TL, Klein-Schwartz W, Caravati EM, Youniss J, Crouch B, Lee S. 1998 Annual report of the American Association of Poison Control Centers Toxic Exposure Surveillance System. Am J Emerg Med. 1999;17(5):435-87.

30. Trenton A, Currier G, Zwemer F. Fatalities associated with therapeutic use and overdose of atypical antipsychotics. CNS Drugs. 2003;17(5):307-24.
31. Dubois D. Toxicology and overdose of atypical antipsychotic medications in children: does newer necessarily mean safer? Curr Opin Pediatr. 2005;17(2):227-33.

32. Aghaienia N, Brahm NC, Lussier KM, Washington NB. Probable quetiapine-mediated prolongation of the QT interval. J Pharm Pract. 2012;24(5):506-12.

33. Tan HH, Hoppe J, Heard K. A systematic review of cardiovascular effects after atypical antipsychotic medication overdose. Am J Emerg Med. 2009;27(5):607-16.

34. Kecskemeti V. Cardiac effects of antipsychotics: mechanism of arrhythmias and sudden cardiac death. Neuropsychopharmacol Hung. 2004;6(1):5-12.

35. Aichhorn W, Marksteiner J, Walch T, Zernig G, Saria A, Kemmler G. Influence of age, gender, body weight and valproate comedication on quetiapine plasma concentrations. Int Clin Psychopharmacol. 2006;21(2):81-5.

36. Hiemke C, Baumann P, Bergemann N, Conca A, Dietmaier O, Egberts K, et al. AGNP consensus guidelines for therapeutic drug monitoring in psychiatry: update 2011. Pharmacopsychiatry. 2011;44(6):195-235.

37. Baumann P, Hiemke C, Ulrich S, Eckermann G, Gaertner I, Gerlach M, et al. The AGNP-TDM expert group consensus guidelines: therapeutic drug monitoring in psychiatry. Pharmacopsychiatry. 2004;37(6):243-65.

38. Brown S, Sweeney R. Overdose and treatment of quetiapine ingestions. J Emerg Nurs. 2007;33(6):582-4.

39. Benson BE, Hoppu K, Troutman WG, Bedry R, Erdman A, Hojer $\mathrm{J}$, et al. Position paper update: gastric lavage for gastrointestinal decontamination. Clin Toxicol (Phila). 2013;51(3):140-6.

40. Burns MJ. The pharmacology and toxicology of atypical antipsychotic agents. J Toxicol. 2001;39(1):1-14.

41. Toxicologists AAoCTEAoPCaC. Position statement and practice guidelines on the use of multi-dose activated charcoal in the treatment of acute poisoning. J Toxicol Clin Toxicol. 1999;37(6): 731-51.

42. Beitland S, Platou ES, Sunde K. Drug-induced long QT syndrome and fatal arrhythmias in the intensive care unit. Acta Anaesthesiol Scand. 2014;58(3):266-72.

43. Gupta A, Lawrence AT, Krishnan K, Kavinsky CJ, Trohman RG. Current concepts in the mechanisms and management of druginduced QT prolongation and torsade de pointes. Am Heart J. 2007;153(6):891-9. 